\title{
Design and Fabrication of Lever Operated Wheelchair for Disabled Person with No Legs
}

\author{
Jagdish P. Choudhary ${ }^{1}$, Poonam G. Choudhary ${ }^{2}$, Kedar M. Kulkarni ${ }^{3}$ \\ Student, Department of Mechanical Engineering, KJEI's Trinity Academy of Engineering, Pune ${ }^{1,2}$ \\ Assistant Professor, Department of Mechanical Engineering, KJEI’s Trinity Academy of Engineering, Pune ${ }^{3}$
}

\begin{abstract}
The design and fabrication of lever operated wheelchair is can be renovated. There are many numbers of people who are suffering from disabilities caused by an accidental injury. Various methods are used for developing manual wheelchair in order to help those people. HMI, HCL and Accelerometer in the wheelchair are some of them used by researchers. These techniques modify the existing design but there are many individuals who cannot manage to pay for advanced model. So, in this deign we are replacing the chain drive mechanism by slider crank mechanism for conveying the force to give motion to wheelchair. The wheelchair is designed in such a way that it requires a less effort by an operator to operate and it is economically affordable as compared to other advanced wheelchair.
\end{abstract}

Keywords: Lever operated wheelchair, Design of wheelchair, Fabrication of Lever Operated Wheelchair, Lever Mechanism

\section{INTRODUCTION}

The design of lever operated wheelchair for disabled person with no legs is remodelled in the work. The lever operated wheelchair, the wheels of bicycle are used instead of push edges. The wheels will be rotated with the help of lever which will be attached to wheels by means of lever operated mechanism. The main motto of this project is to give the replica which will require less effort than the conventional wheelchair and it will have low cost in comparison with the advanced wheelchairs available in the market. There are people who cannot buy the Automatic power wheelchairs for daily use. So, this wheelchair will be the better option for those people.

\section{LITERATURE REVIEW}

In this literature review the work done on wheelchair and modification of it by various researchers is introduced.

1. Gaurav Singh Parihar \& Sanjay Singh Azad worked on Design and Analysis of Handicapped Steering Tricycle and observed that conventional tricycles for handicapped require a lot of human effort to operate. They generally come with separate arrangements for providing motion and giving direction to the vehicle. These separate arrangements cause asymmetric use of hands and this result in discomfort of the rider.

2. Nikhil V. Bhende has done Design and Fabrication of Lever Propelled Wheelchair. This work includes the design of lever propelled wheelchair. In the design of lever propelled wheelchair, the wheels of bicycle will be used instead of push rim. The wheels will be rotated with the help of lever which will be attached to wheels by means of chain sprocket mechanism. The main motto of this project is to give the model which will require less effort than the conventional wheelchair and it will have low cost in comparison with the advanced wheelchairs available in the market. 3. Ravi Solanki el al. has done a work on Modification of Delta Tricycle. In this work chain drive mechanism is replaced by Single slider mechanism is used to transmit power for driving tricycle which is most useful and economical as compared to the other tricycle. This tricycle is mostly useful for elder and handicapped people. Design of tricycle is simple, easy to operate and maintenance is very less. The operational efforts required less and hence single slider mechanism is an advantage of the tricycle.

4. Sorathiya Mehul \& Utkarsh Prajapati have done a Design and Implementation of Tricycle for Handicapped Person. They studied that modified tricycle for handicapped person is based on assisting and supporting handicapped individuals with one functional leg and one functional hand to easily ride bicycle and to make them feel confident performing work like healthy person. In this work the conventional tricycle design was improved and some of its parts were modified in order to suit the utilization by such category of the people.

5. V.B. Vaidya has done a research on Design and fabrication of Wheelchair Cum Tricycle for Physically Challenged and Elder people. This research is about the development of traditional manual operated wheelchair cum tricycle is rear wheel drive in which chain drive mechanism replaced with single slider drive mechanism. The design concept of this model is taken from manually operated tricycle and railroad car. This wheelchair cum tricycle is useful 


\section{International Advanced Research Journal in Science, Engineering and Technology}

Vol. 6, Issue 1, January 2019

for handicapped person. This modified tricycle gives the both advantages of wheelchair (for short distance or in-door use) as well as tricycle (for long distance use) in one machine.

6. Michael C. Godoy has studied on Ergonomics Analysis of Tricycle Sidecar Seats. The purpose of this study is to analyze the variability in design of the tricycles in Lipa City, Philippines and propose a standard ergonomically designed tricycle sidecar seat for a greater population. The study was conducted at 26 tricycle terminals with 232 tricycle samples within Lipa City proper including the public market area where 400 commuters were given questionnaires to determine the risk factors associated with the existing tricycle sidecar seat design. Anthropometric measurements of 100 males and 100 female commuters were obtained together with the sidecar dimensions of 232 tricycles to substantiate the observed variations in design.

7. W. Choromanski, K. fiok has researched on Optimizing the Lever Propelling System for Manual Wheelchair. The research concerns the optimization of manual wheelchairs with a lever propelling system. Lever-driven manual wheelchairs are a promising wheelchair group; however, they still need to be improved in order to compete successfully with classic manual push rim-driven wheelchairs. Also, despite all manual wheelchairs human work efficiency during propulsion plays an important role, there is not enough research carried out that would focus on this problem regarding lever-driven wheelchairs. The research, presented, according to the authors' intention, is to make this knowledge gap smaller. The article describes an analytical optimization method for adjusting important lever-drive system parameters - levers length and its axis of rotation position - to individual human anthropometry. The method is based on experimental data regarding maximum human push capabilities acquired in another study.

8. Lucas H.V. Vander Woude \& Ingrid vriend have done an experimental work on Mechanical Advantage in Wheelchair Lever Propulsion. In this experimental study on a prototype lever-propelled wheelchair, the effect of a range of mechanical advantages (MA) on physical strain, oxygen uptake, energy cost, mechanical efficiency, stroke frequency and perceived exertion was examined. Nine out of 10 male non wheelchair users successfully performed five submaximal tests on a motor-driven treadmill in a prototype bi-manual asynchronous lever-propelled tricycle.

Literature review summarizes various method uses to improve a manual wheelchair in operating area like replacing chain drive mechanism to slider crank mechanism. It also focuses on reducing the effort required by the operator to operate a wheelchair, ergonomics of chair seat \& cost reduction.

\section{METHEDOLOGY}

With the need of wheelchair for disabled person at low cost and ease in motion various types of wheelchairs have been studied to obtain low cost and easy handling wheelchair. The design was developed by using CATIA software. The flowchart in fig 1 represents a methodology adopted for a current work described.

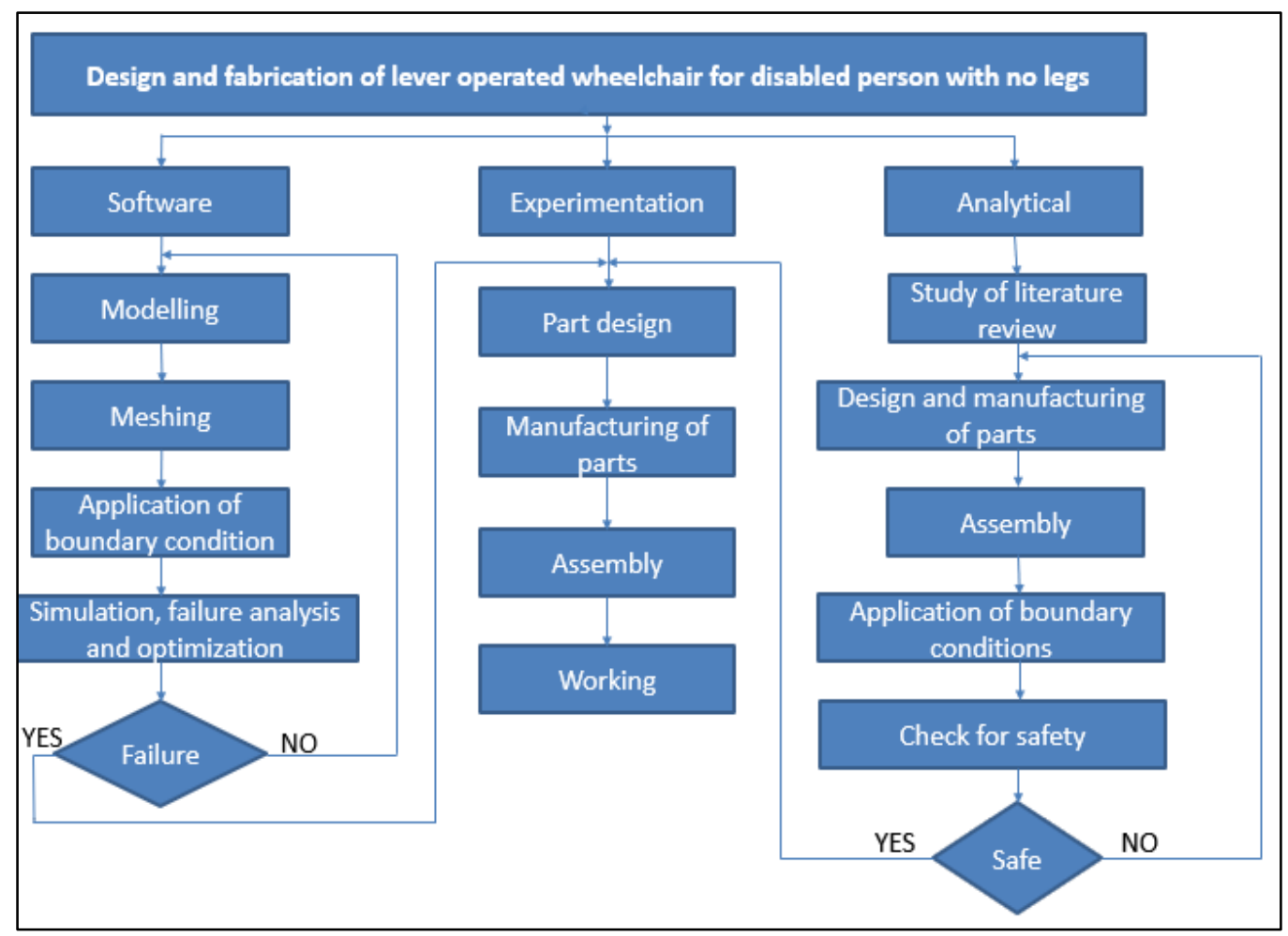

Figure. 1. Methodology of Proposed Design. 


\section{International Advanced Research Journal in Science, Engineering and Technology}

Vol. 6, Issue 1, January 2019

\section{WORKING PRINCIPLE AND MODEL DESIGN}

The working principle applied on an intended model is discussed below.

\subsection{Working Principle}

For the application of the force on steering in forward and backward direction lever and crank is provided, the motion to wheelchair by converting the sliding motion into rotary motion. The different positions are shown in figure 2 \& 3 .

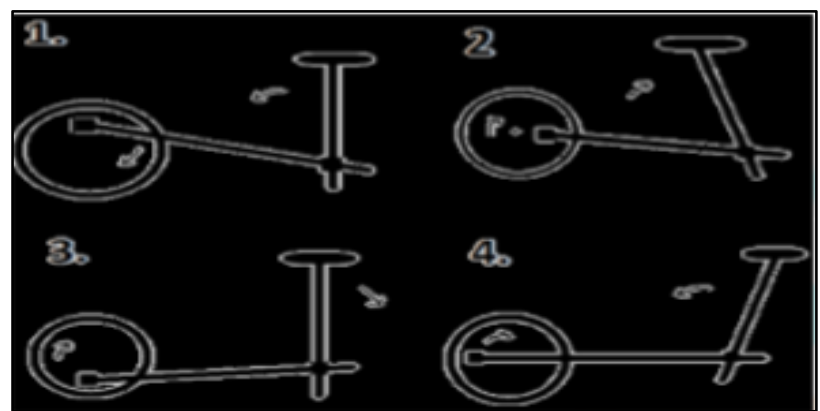

Figure 2. Different Position for Forward Direction

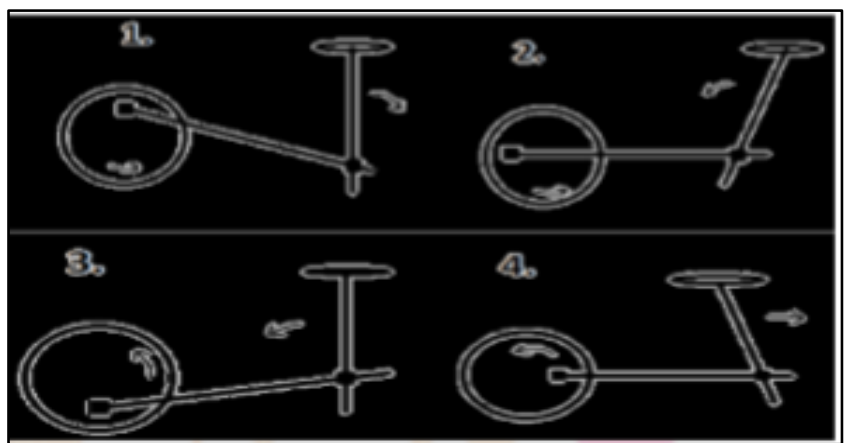

Figure 3.Different Position for Backward Direction

$>\quad$ The motion of direction of wheelchair is controlled by steering.

$>\quad$ The device is operated by to and fro motion of steering which help to rotate the wheel, the turning action takes place by tilting the steering forward and backward direction.

\subsection{Model Design}

The assembly in fig 4 is done by combining all design parts. The dimensions of parts may change according to placement of mechanism for movement and turning motion.

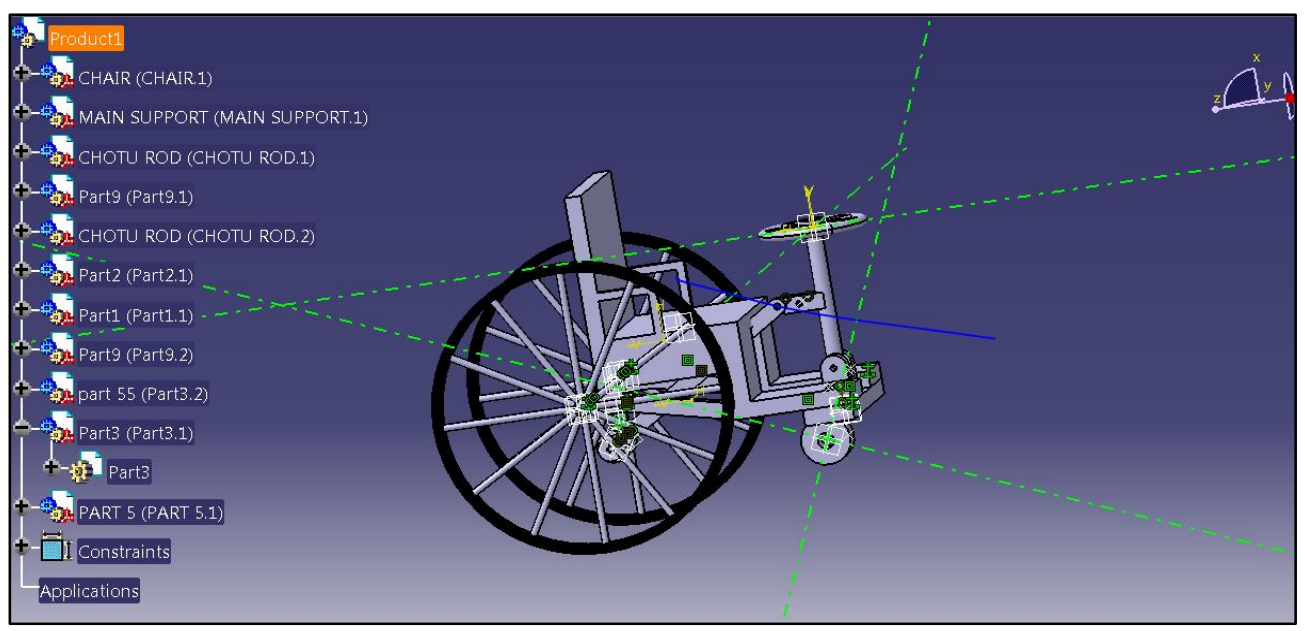

Figure 4. Overview of Model 


\section{International Advanced Research Journal in Science, Engineering and Technology}

Vol. 6, Issue 1, January 2019

\section{MATERIAL SELECTION}

Every material has different property with different range. In order to select a proper material for our wheelchair, some important properties of different material are studied.

\subsection{Mechanical Properties of Material}

The following table shows a different mechanical property of a different material on basis of which the material is going to be selected.

\begin{tabular}{|l|c|c|c|c|}
\hline Sr.No & Material & $\begin{array}{c}\text { Young's Modulus } \\
\text { (GPa) }\end{array}$ & $\begin{array}{c}\text { Ultimate Tensile } \\
\text { Strength } \\
\text { (MPa) }\end{array}$ & $\begin{array}{c}\text { Yield Strength } \\
\text { (MPa) }\end{array}$ \\
\hline 1. & Aluminium (Al) & 69 & 110 & 95 \\
\hline 2. & $\begin{array}{l}\text { Titanium } \\
\text { Ti-6Al-4V } \\
\text { (Grade 5) }\end{array}$ & 113.8 & 950 & 880 \\
\hline 3. & $\begin{array}{c}\text { Stainless Steel } \\
\text { Grade 304 }\end{array}$ & $190-200$ & 505 & 215 \\
\hline $4 . \quad \begin{array}{l}\text { Mild Steel } \\
\text { (A36 Steel) }\end{array}$ & 200 & $400-500$ & 250 \\
\hline
\end{tabular}

Table 1. Mechanical Property of Materials

From table 1, it has been observed that the titanium is having high values for young's modulus, ultimate tensile strength and yield strength respectively. But due to economic aspect it is not desirable as it is very costly. Aluminium can be also use for the design of proposed model as it is light in weight and less costly too. But welding of aluminium material is problem due to its low thermal expansion properties. Also, aluminium requires a special type of welding which costs more and cannot bear a heavy load. Therefore, steel is widely used for manufacturing of wheelchair. It can be easily weld, easily available in the market and bear a heavy load.

\subsection{Process of Material Selection}

The steel material is widely used for a manufacturing of wheelchair. But looking towards an operator safety and economic aspect too it is necessary to choose an optimum material for manufacturing of wheelchair. The flow chart form fig 5 shows a step involved in selection of material.

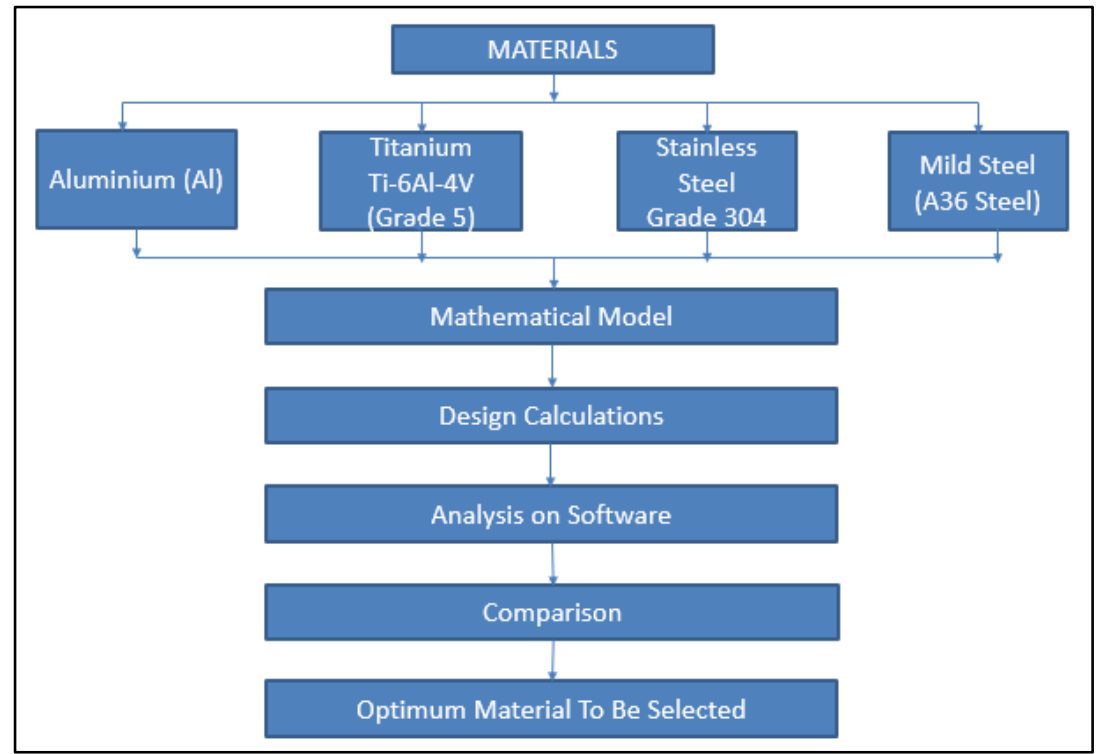

Figure 5. Flowchart for Material Selection 


\section{International Advanced Research Journal in Science, Engineering and Technology}

Vol. 6, Issue 1, January 2019

An operator safety can be accomplished by analysing a model in a software like Ansys, Hyper mesh, etc. by applying load and boundary conditions.

\section{CONCLUSION}

Optimization, analysis and design of wheelchair can be carried out to Design and Fabricate a Lever Operated Wheelchair for Disabled Person with No Legs. The existing manual wheelchair is replaced by chain drive mechanism to slider crank mechanism as shown in proposed design. The variety material have been studied \& experimented for the manufacturing of wheelchair by comparing their mechanical properties. A flowchart is prepared in order to select an optimum material for a wheelchair. The selection of material takes care of operator safety, ease of handling, maximum load that can be apply on wheelchair and last but not the least cost of wheelchair.

\section{REFERENCES}

[1]. Gaurav Singh Parihar, Sanjay Singh Azad. "Design and Analysis of Handicapped Steering Tricycle" IRJET-2018.

[2]. Prof. Nikhil V. Bhende. "Design and Fabrication of Lever Propelled Wheelchair" IRJET - 2017.

[3]. Ravi Solanki, Jigar Rathod, Vaibhav Patel, Himanshu Mardhekar. "Modification of Delta Tricycle" IJNRD-2017.

[4]. Sorathiya Mehul, Utkarsh Prajapati. "Design and Implementation of Tricycle for Handicapped Person" IJAERD-2017.

[5]. V. B. Vaidya. "Design and fabrication of Wheelchair Cum Tricycle for Physically Challenged and Elder people" IJSRD-2016.

[6]. Michael C. Godoy. "Ergonomics Analysis of Tricycle Sidecar Seats" Asia Pacific Journal of Multidisciplinary Research-2015.

[7]. W. Choromanski, K. fiok. "Optimizing the Lever Propelling System for Manual Wheelchair" Bulletin of The Polish Academy of Sciences-2012.

[8]. Lucas H.V. Vander Woude, Ingrid vriend. "Mechanical Advantage in Wheelchair Lever Propulsion" Journal of Rehabilitation Research and Development-1997. 